\title{
THERMAL STABILITY ANALYSIS OF GEVO JET FUEL USING ELLIPSOMETRY
}

\author{
Leigh Nash ${ }^{1}$, Jennifer Klettlinger ${ }^{2}$, Subith Vasu ${ }^{1}$ \\ ${ }^{1}$ Center for Advanced Turbomachinery and Energy Research (CATER) \\ Mechanical and Aerospace Engineering \\ University of Central Florida \\ Orlando 32816, Florida, USA \\ leighn2010@knights.ucf.edu \\ ${ }^{2}$ NASA Glenn Research Center \\ Cleveland 44135, Ohio, USA
}

\section{ABSTRACT}

Thermal stability is an important characteristic of alternative fuels that must be evaluated before they can be used in aviation engines. This characteristic is of great importance to the effectiveness of the fuel as a coolant and to the engine's combustion performance. The thermal stability of Gevo fuel, an alcohol to jet fuel made from plant feedstock was studied. This analysis was used to make comments on the effectiveness of the current thermal stability test standard. This work was performed using a spectroscopic ellipsometer to measure the thickness of deposits left on aluminum substrates. It was observed that Gevo deposit thickness increased slowly up to $375{ }^{\circ} \mathrm{C}$ and much more rapidly after that point. Similar behavior was observed in JP-8 fuel. Comparisons were also made between color standard ratings and ellipsometric thickness measurements, and it was found that in some cases, darker colors did not indicate thicker deposits. Reference tubes were used to validate the optical models used in this work, and different optical constants were found to best model the results than what are published in the ASTM D3241 test method for thermal stability.

\section{NOMENCLATURE}

$A=$ Proportional to the height of the peak of the $\varepsilon_{I}$ curve. This is a material specific constant $[\mathrm{eV}]$

$\mathrm{C}=$ Proportional to the full width at half maximum of the peak in the $\varepsilon_{\mathrm{I}}$ curve. This is a material specific constant $[\mathrm{eV}]$

$\mathrm{E}=$ Photon energy of incoming light $[\mathrm{eV}]$

$\mathrm{E}_{0}=$ Photon energy where the peak of the $\varepsilon_{\mathrm{I}}$ curve occurs $[\mathrm{eV}]$

$\mathrm{E}_{\mathrm{g}}=$ Photon energy where $\varepsilon_{\mathrm{I}}$ is first nonzero $[\mathrm{eV}]$

$\mathrm{eV}=$ Electron volts
HLPS $=$ Hot Liquid Process Simulator

$\mathrm{j}=$ The imaginary number

$\mathrm{k}=$ Coefficient of extinction

$\mathrm{N}=$ Complex index of refraction

$\mathrm{n}=$ Index of refraction

$\mathrm{R}^{\mathrm{p}}=$ Total reflectance coefficient in the direction parallel to the light propagation direction

$\mathrm{R}^{\mathrm{S}}=$ Total reflectance coefficient in the direction perpendicular to the light propagation direction

$\mathrm{r}_{\mathrm{ij}}^{\mathrm{p}, \mathrm{s}}=$ Reflectance coefficient between the $\mathrm{i}^{\text {th }}$ and $\mathrm{j}^{\text {th }}$ surface in the parallel or perpendicular direction respectively

$\mathrm{t}=$ Thickness $[\mathrm{nm}]$

$\beta=$ Phase change through one layer of film [rad]

$\Delta=$ Phase change across the sample [rad]

$\varepsilon=$ Dielectric function

$\varepsilon_{\infty}=$ Value of the $\varepsilon_{\mathrm{r}}$ curve as the energy of the incoming light becomes large $[\mathrm{eV}]$

$\lambda=$ Wavelength $[\mathrm{nm}]$

$\phi=$ Angle between the light beam and the sample normal [rad]

$\Psi=$ Ratio of the total reflectance coefficients

$\chi^{2}=$ Goodness of fit parameter

\section{INTRODUCTION}

Alternative jet fuels are of interest to the aviation community because of rising oil costs, the need to secure a consistent fuel supply, and the desire for cleaner burning engines [1]. Before alternative fuels are certified for use in 
flight they are rigorously tested and qualified. An important fuel property that must be characterized is the thermal stability, which is a measure of the degree to which a fuel breaks down when it is heated. As a weight and space saving measure, the fuel in an aircraft is often used as engine coolant in addition to being the propellant, especially in military applications. Preheating the fuel in this way can cause it to break down inside the engine plumbing, fouling the lines and leading to a loss of fuel flow. Knowledge of the way a fuel thermally decomposes and the amount of deposit that is formed is essential for anticipating maintenance schedules and possible fuel flow issues. A basic level of thermal stability is also required of all alternative fuels for adoption as acceptable jet fuels.

In the past, the ASTM Standard Test Method for Thermal Oxidation Stability of Aviation Turbine Fuels (D3241), also known as the Jet Fuel Thermal Oxidation Test (JFTOT) relied solely on a comparison between a color standard and the deposits left on a heated tube after the fuel was flowed over it to determine thermal stability. A fuel was defined as thermally stable at a particular temperature if the deposit rated a 3 or less on the color scale [2] shown in Figure 1. The tubes were placed into an illuminated box called the Visual Tube Rater, and an operator would compare the color of the deposit on the tube to the color standard to determine the most appropriate rating. These comparisons were deemed to be subjective and non-repeatable [3], which led to the implementation of ellipsometry to measure film deposit thicknesses [4].

Ellipsometry allows objective measurements of the film thickness to be made, yielding quantitative data that can be statistically analyzed, which is not true of the color standard. Using the color standard to define the thermal stability of a fuel yields only a rating of the color of the deposit. In addition, the color standard is only applicable to conventional fuels on aluminum substrates. Ellipsometry is more versatile in that it can be used to analyze the sample regardless of the composition of the film or the substrate. Significant details about the film are lost when the tube is assigned a color rating as the color categories are broad. Samples that receive the same color rating may have important differences between them. Small changes to the film that do not manifest themselves as a color change are lost in this way, but are detectable by ellipsometry. The ellipsometric thermal stability criteria requires the thickest part of the deposit be less than 85 $\mathrm{nm}$, and this technique is sensitive to minute changes in the deposit thickness, making it extremely precise. Ellipsometry can also be used to study the roughness of a surface, the composition of the sample, and the optical constants of the material in addition to the thickness. In this study, the thickness is reported because it is the parameter chosen to represent the thermal stability in the ASTM standard.

Previous studies have been conducted using ellipsometry to measure the thermal stability of jet fuels. These include Baker et al. [3] who investigated traditional fuels, Nash et al. [4, 5] on Sasol IPK (an alternative jet fuel), and Browne et al [6] on JP-8 (military equivalent of Jet A).

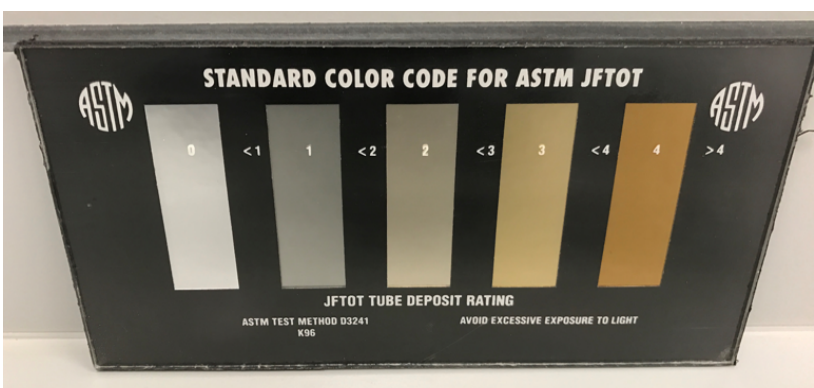

Figure 1: JFTOT Color Standard. There are 10 color designations including $0,<1,1,<2,2,<3,3,<4,4$, and $>4$. The 0 rating corresponds to a clean tube and the color of the deposit gets darker as the rating number increases.

Gevo jet fuel was the primary fuel of interest in this work. This fuel has very few components as evidenced by Table 1 which shows the composition of this fuel and Jet A, a traditional jet fuel for comparison. Traditional jet fuels typically have thousands of components. Gevo is isobutanol $\left(\mathrm{C}_{4} \mathrm{H}_{10} \mathrm{O}\right)$ made from plant derived feedstock through an alcohol to jet (ATJ) fuel process. Only the final product of the ATJ process was tested in this work. This fuel is more than 99 percent isoparaffins by percentage weight, with less than one percent being made up of normal paraffins, cycloparaffins, and aromatics.

Table 1: Composition of Gevo Jet Fuel [Linda Shafer and Tim Edwards]

\begin{tabular}{|l|l|l|l|l|}
\hline Fuel & $\begin{array}{l}\text { Iso- } \\
\text { paraffins } \\
(\text { mass\% }\end{array}$ & $\begin{array}{l}\text { Normal } \\
\text { paraffins } \\
(\text { mass\%) }\end{array}$ & $\begin{array}{l}\text { Cyclo- } \\
\text { paraffins } \\
\text { (mass\%) }\end{array}$ & $\begin{array}{l}\text { Aromatics } \\
(\text { mass } \%)\end{array}$ \\
\hline Gevo & 99.43 & 0.02 & 0.54 & 0.01 \\
\hline Jet A & 29 & 20 & 32 & 17 \\
\hline
\end{tabular}

\section{EXPERIMENTAL METHOD}

\section{$\underline{\text { Background }}$}

In the most basic sense, an ellipsometer is made up of a light source, polarizer, detector, and analyzer. After leaving the source, the light is given a linear polarization. The light then encounters the sample. After reflection from the film, it is elliptically polarized, and it enters the detector (illustrated in Figure 2). The polarization of the light can be better understood if the light is imagined as a series of rays oscillating up and down, with the amplitude of the rays changing to follow the path of the wave. If these rays are viewed normal to the direction in which they are moving, they trace out the shape of an ellipse when the light is elliptically polarized. The shape of this ellipse indicates the amplitude and phase of the components of the light traveling parallel and perpendicular to the plane of incidence, which are the parameters measured by the ellipsometer. Ellipsometry is named for this use of elliptically polarized light. 


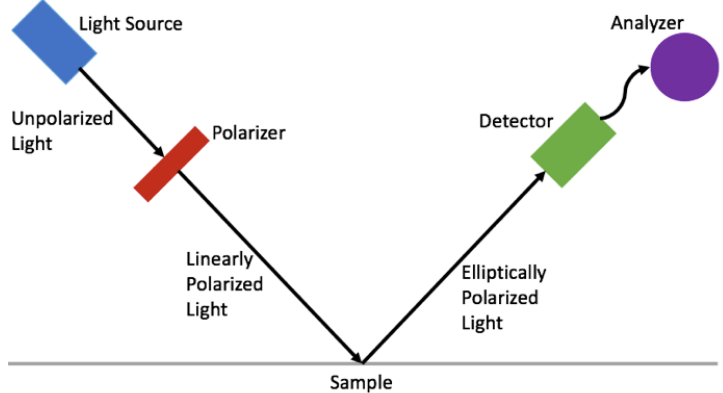

Figure 2: Primary components of the ellipsometer.

When light crosses a boundary between two materials, such as from the ambient air to a deposit film, the phase and intensity of the beam changes. The light reflects and refracts according to Snell's Law, which is given in Equation 1.

$$
n_{0} \sin \phi_{i}=n_{1} \sin \phi_{t}
$$

A portion of the incoming light is reflected from the surface at an angle equal to the angle of incidence. The remainder of the light transmits into the material at a refracted angle given by Snell's law (shown in Figure 3).

The incoming light reflects and refracts at the contact plane between the two materials, and in a multi-layer material, this occurs at each interface (see Figure 3). This means that the overall reflected beam is made up of components from each interfacial interaction. The properties of this beam are tracked though each medium change, and in this way, the thickness of the layer can be determined using the Fresnel equations (Equation 2), where $\beta$ is the phase change for a beam of light that passes twice through the material given by Equation 3. $R^{p}$ and $R^{s}$ are the overall reflectance coefficients for the sample as a whole. $\beta$ is important in this work because it contains the thickness of the layer as an input parameter, which is the parameter of interest. Equations 4 and 5 define the individual reflectance coefficients for each layer in the sample, which are ratios of the intensity of the incoming light to that of the outgoing, and these coefficients are contained in the Fresnel relations. Equation 6 defines the complex index of refraction of each layer, $\mathrm{N}_{\mathrm{i}}$, which is a convenient way of representing the index of refraction (n) and the coefficient of extinction $(\mathrm{k})$. This parameter is used in Equations 3 and 4. In Equations 2, 4, and 5 , the $\mathrm{p}$ superscript indicates that the equation pertains to the component of the light oscillating parallel to the plane of incidence, and the $s$ superscript indicates that the equation pertains to the component oscillating perpendicular to the incidence plane.

$$
R^{p, s}=\frac{r_{12}^{p, s}+r_{23}^{p, s} \exp (-j 2 \beta)}{1+{r_{12}}^{p, s} r_{23}^{p, s} \exp (-j 2 \beta)}
$$

$$
\begin{gathered}
\beta=2 \pi\left(\frac{t}{\lambda}\right) N_{2} \cos \left(\phi_{2}\right) \\
r_{i j}^{p}=\frac{N_{j} \cos \phi_{i}-N_{i} \cos \phi_{j}}{N_{j} \cos \phi_{i}+N_{i} \cos \phi_{j}} \\
r_{i j}{ }^{s}=\frac{N_{i} \cos \phi_{i}-N_{j} \cos \phi_{j}}{N_{i} \cos \phi_{i}+N_{j} \cos \phi_{j}} \\
N_{i}=n_{i}-j k_{i}
\end{gathered}
$$

The equations presented here are for a three component sample (the ambient, the film, and the substrate), but the same pattern can be extended for a different number of components to account for a film with multiple layers.

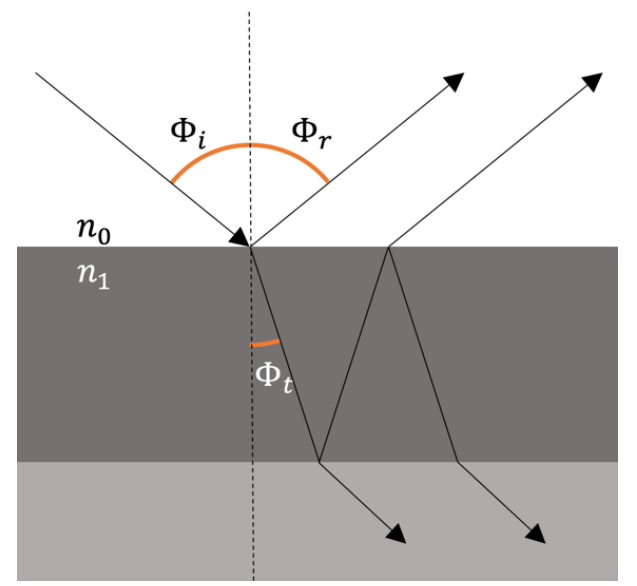

Figure 3: Light behavior at an interface. The overall reflected beam is made up of components that come from each interfacial interaction.

Ellipsometry can be used to determine the thickness of thin films only. In this context, thin is defined to mean that at least a detectable portion of the light that is incident on the sample reaches the substrate and returns back the ambient so that it is collected by the detector. If the light is entirely absorbed by the sample before reaching the ambient again, the information containing the thickness of the film is lost with the light. In Figure 3, the second reflected ray (the ray reflected at the boundary between the dark and light gray materials) satisfies this condition.

\section{$\underline{\text { Sample Preparation and Data Collection Method }}$}

The samples were prepared using an Alcor Hot Liquid Process Simulator model HLPS-400, following the JFTOT procedure given in ASTM D3241. A schematic of the HLPS can be seen in Figure 4. The sample is colored light gray and labeled "test tube." The tube is not positioned specially with regards to angular positon, as the fuel flows over the entire 
outside surface. The fuel flows over the sample starting from the fuel reservoir and following the black arrows shown in the figure. The fuel is heated only by passing over the heated tube surface to simulate how the fuel would be heated when it passes over hot components in an aircraft engine. The tube is resistively heated, and its temperature is kept constant by controlling the voltage applied across the tube. The standard requires that an acceptable fuel be stable to at least $260{ }^{\circ} \mathrm{C}$, so testing begins at this point. The fuel is flowed through a cylindrical annulus surrounding the test tube at a rate of 3 cubic centimeters per minute for 150 minutes. Then the tube is removed from the HLPS and allowed to cool. Any deposit on the tube is compared to the color standard and the tube is given a numerical rating from 0 to 4 . If the tube receives a passing rating $(\leq 3)$, the test temperature is increased by $5{ }^{\circ} \mathrm{C}$ and the test is run again, starting with a new clean tube. Once a failure occurs, the highest passing temperature is defined as the thermal breakpoint of the fuel, and the fuel is considered thermally unstable above this breakpoint temperature. This completes the traditional JFTOT procedure. The ellipsometric measurements are made after the conclusion of the traditional JFTOT.

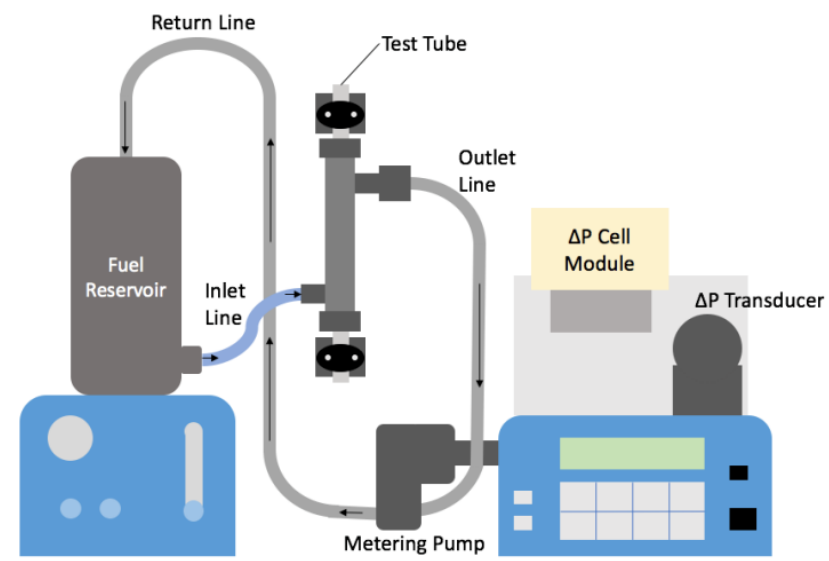

Figure 4: Hot Liquid Process Simulator schematic. Fuel is pumped out of the reservoir, over the test tube, and then back into the reservoir at a rate controlled by the metering pump.

A Horiba Scientific spectroscopic ellipsometer (Auto SE) was used to make the ellipsometric measurements presented in this study and is shown in Figure 5. The Auto SE has a spectral range of 400 to $1100 \mathrm{~nm}$ and $70^{\circ}$ angle of incidence. The sample viewer is a CCD camera with a field of view of 1.33 by $1 \mathrm{~mm}$ and a resolution of $10 \mu \mathrm{m}$. A 70 by $250 \mu \mathrm{m}$ spot size with the long side oriented along the length of the tube was used in order to minimize the effect of the tubes' curved surfaces.

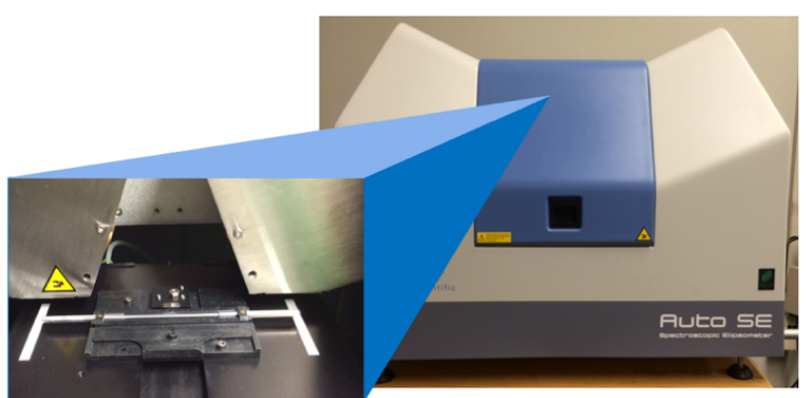

Figure 5: Horiba Scientific Auto SE. The expanded view shows the tube mount on the positioning stage. The silver boxes on either side of the tube house the optical components needed to perform the ellipsometric measurement.

After preparation in the HLPS and analysis using the color standard, the completely cooled tube is placed into the ellipsometer. All ellipsometric measurements are done at room temperature. There is a mount inside the ellipsometer to hold the tube in place, which is on a stage that can move in all three spatial directions to position the sample for viewing by the camera.

\section{Optical Modeling}

The ellipsometer measures $\Psi$, which is the ratio of the magnitude of the reflectance coefficients as shown in Equation 7, as well as $\Delta$ which is the phase difference between the incoming and outgoing light beams, shown in Equation 8. Equation 9 relates these two parameters and is called the fundamental equation of ellipsometry. $\Psi$ and $\Delta$ are measured over a range of wavelengths, and these points constitute the experimental data. The index of refraction (n) and coefficient of extinction (k) can be calculated from $\Delta$ and $\Psi$ from the fundamental equation of ellipsometry and the Fresnel relations. Optical models are then used to obtain theoretical $n$ and $\mathrm{k}$ values over the same wavelength range. Equations 2 through 6 are used with the theoretical optical constants to produce theoretical reflectance coefficients with an assumed thickness, which are further used in Equations 7 through 9 to obtain theoretical $\Psi$ and $\Delta$ values. The theoretical $\Psi$ and $\Delta$ are compared to the experimental results, and the parameter $\chi^{2}$ is used to quantify the adequacy of the fit (the lower the $\chi^{2}$ the closer the fit). The assumed thickness value is incremented, and the process is iterated until a satisfactory $\chi^{2}$ is found. The thickness at which the lowest $\chi^{2}$ occurs is accepted as the thickness at that tube location. This process is repeated for 58 points, spaced $2 \mathrm{~mm}$ apart down the length of the tube to yield the thickness profile.

$$
\tan \Psi=\frac{\left|R^{p}\right|}{\left|R^{s}\right|}
$$


$\Delta=$ phase of incoming light - phase of outgoing light

$$
\tan \Psi e^{i \Delta}=\frac{R^{p}}{R^{s}}
$$

The Tauc-Lorentz dispersion [7] was used to generate the theoretical $\mathrm{n}$ and $\mathrm{k}$ curves for these samples. This particular dispersion was chosen for reasons that will be explained in the validation section. The Tauc-Lorentz dispersion is defined in terms of the dielectric function $\varepsilon$, which is equal to the complex index of refraction squared. Also, these equations that make up this dispersion are functions of photon energy of the incoming light, which can easily be converted to wavelength. This dispersion describes a shape given qualitatively by Figure 6 . Here, the red curve represents the real part of the dielectric function, and the blue curve represents the real part. In this figure and the following equations, the subscript $r$ refers to the component of the real component of the dielectric constant, and the subscript i refers to the imaginary part.

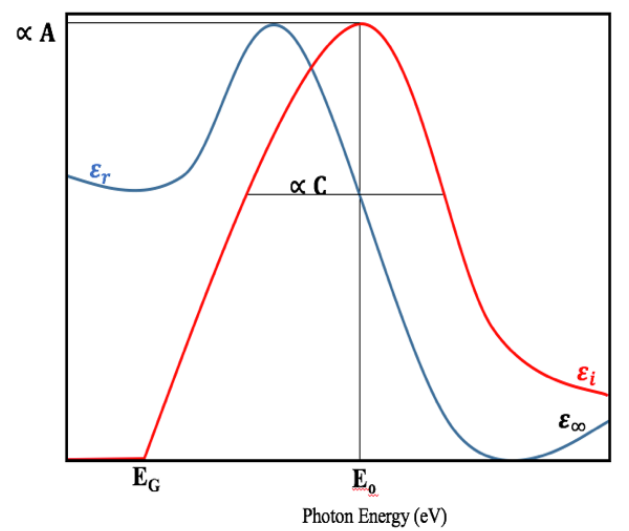

Figure 6: Tauc-Lorentz dispersion formula shape. This dispersion was used in modeling the samples in this study.

The important parameters in this dispersion are $\mathrm{E}_{0}$, which is the location of the peak of the $\varepsilon_{\mathrm{i}}$ curve, $\mathrm{E}_{\mathrm{g}}$ which is the first energy at which $\varepsilon_{\mathrm{i}}$ is non-zero, $\mathrm{C}$, which is proportional to the full width at half maximum of the peak, $\mathrm{A}$ which is proportional to the peak height, and $\varepsilon_{\infty}$ is the value of the $\varepsilon_{\mathrm{r}}$ curve as the energy of the incoming light becomes large. The main point of this discussion is that the Tauc-Lorentz dispersion can be used to generate theoretical $\mathrm{n}$ and $\mathrm{k}$ values that are compared to those obtained by the ellipsometer. In this analysis, only the thickness is varied, or fitted. All other quantities are assumed to be known material constants, and are defined based on the model chosen.

\section{Reference Tube Validation}

Eight reference tubes were obtained for analysis from Wright Patterson Air Force Base. The researchers at WPAFB produced aluminum tubes with carbon deposits on them with known thicknesses and measured the thicknesses with their ellipsometric and interferometric tube raters. This provided an opportunity to validate the optical models used in determining the deposit thicknesses on the tubes exposed to the Gevo and JP-8 fuels.

These reference tubes were created by plasma sputtering a carbon target, and rotating the tube to produce an even distribution around the circumference. Carbon was deposited over approximately $10 \mathrm{~mm}$ long sections of each tube. The rest of the surface was covered with Kapton tape during deposition which was removed afterwards. The covered sections were cleaned with isopropyl alcohol after the deposition process was finished. This produced plateau-like thickness profiles with well-defined edges on an otherwise clean tube.

The theoretical deposit thicknesses were determined using a deposition rate method. First, a thick carbon film was deposited on a tube over a controlled length of time. This film was thick enough to measure its depth using profilometry. Using the known deposit thickness and exposure time, the deposition rate in terms of thickness per unit time was calculated. Then, tubes with specific thicknesses could be produced by exposing them to the carbon sputtering for a specific length of time. This method assumes that the deposition rate is constant with time, and that it is constant with deposit thickness, meaning that the deposition rate is the same regardless of the thickness of the deposit already present on the tube.

Because these tubes had theoretically known deposit thicknesses and easy to predict profile shapes, they were used to validate the optical models used to determine the deposit thicknesses on the samples exposed to the jet fuels. This provided an opportunity to evaluate various models and their ability to fit thin carbon films. The films on the reference tubes were compositionally similar (both carbon) to those produced by the heated jet fuels, and it can be assumed that the models treat them in roughly the same manner. In addition, since the model is being fit to each tube individually, the samples need not be completely identical for the validation to hold. The main point is to obtain a result as close as possible to the reference thickness to validate the optical modeling process. Various dispersion types were tried to model these results. New amorphous and Tauc-Lorentz dispersions were investigated, and both were found to give the expected thickness profile shapes, but very different thickness magnitudes. Reference material models for aluminum and aluminum oxide were also tested, and found to yield the appropriate thickness profile shape, but the magnitude of the deposit was always approximately twice the theoretically known thickness value. The Tauc-Lorentz dispersion was found to match most of the reference tubes close to the 
theoretically known values. Table 2 summarizes these results, and Figure 7 shows a comparison of the thickness profiles that result from the new amorphous, Tauc-Lorentz, and reference material models.

Table 2: Reference tube results. Average Measured Thickness based on Tauc-Lorentz model

\begin{tabular}{|l|l|l|l|}
\hline $\begin{array}{l}\text { Tube } \\
\text { ID }\end{array}$ & $\begin{array}{l}\text { Known } \\
\text { Thickness }(\mathrm{nm})\end{array}$ & $\begin{array}{l}\text { Average Measured } \\
\text { Thickness }(\mathrm{nm}) \\
( \pm 0.5 \mathrm{~nm})\end{array}$ & $\begin{array}{l}\text { Percent } \\
\text { Difference }\end{array}$ \\
\hline 62 & 25 & 19.9 & 22.7 \\
\hline 385 & 30 & 27.8 & 7.6 \\
\hline 389 & 40 & 39.1 & 2.2 \\
\hline 212 & 50 & 50.9 & 1.8 \\
\hline 626 & 60 & 70.4 & 16.0 \\
\hline 498 & 75 & 73.6 & 1.9 \\
\hline 228 & 90 & 61.3 & 37.9 \\
\hline 414 & 255 & 224.2 & 12.9 \\
\hline
\end{tabular}

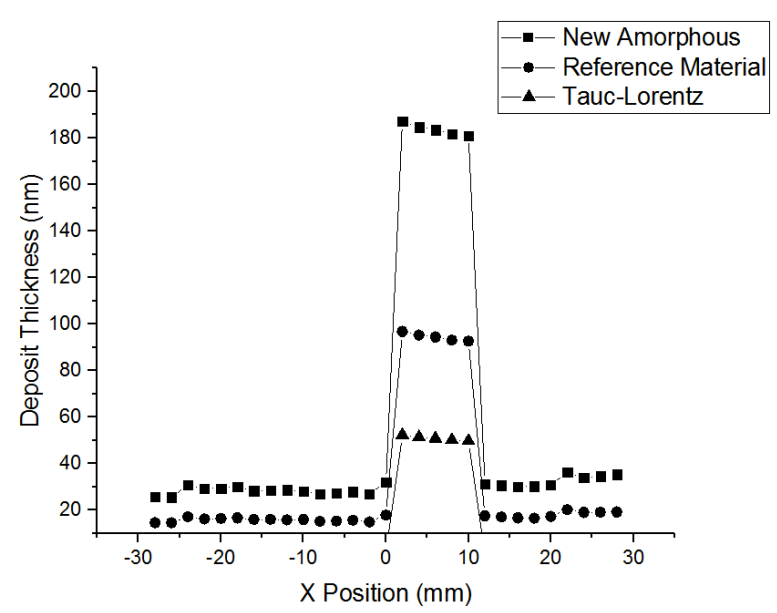

Figure 7: Model comparison for $50 \mathrm{~nm}$ deposit thickness reference tube (tube ID 212). The thickness is measured here and the uncertainty in the measurement solely from the ellipsometer is plus or minus $0.5 \mathrm{~nm}$.

A few of the tubes were not matched precisely by this model, but it is possible that these tubes were not actually labeled with the correct reference thicknesses. The reportedly $25 \mathrm{~nm}$ deposit measured approximately $20 \mathrm{~nm}$. This thinnest reference deposit would be most sensitive to start up phenomena. It seems likely that the deposition was not completely constant with time. The rate might be different at the beginning of the process, when the deposit is forming on the clean aluminum surface, than at the middle or end, when it is depositing on an already carbon coated surface. The percent difference would also be most sensitive to discrepancies in this case because each nanometer of film is a larger portion of the whole in this thinnest deposit. The reportedly $90 \mathrm{~nm}$ reference tube was also not particularly well matched. The models measured $60 \mathrm{~nm}$ for this tube. This sample is unique in that its visual appearance did not appear to follow the trend of the others. Several of the other reference tubes had gray deposits on them that grew darker visually as the deposit got thicker. The $90 \mathrm{~nm}$ tube appeared very light, lighter than several of the tubes that had reportedly thinner deposits, which seems out of place. Although the eye is very insensitive to these types of changes, and these findings cannot be used with any certainty, it seems odd that this tube did not follow the pattern of the others, and was enough to call into question the theoretically known thickness in this case, especially because the model is accurate for the other tubes. It would be impossible for a single model to represent every tube perfectly, but the one selected is the best for this application. Figure 8 shows the reference tubes in order of increasing theoretical deposit thickness from top to bottom.

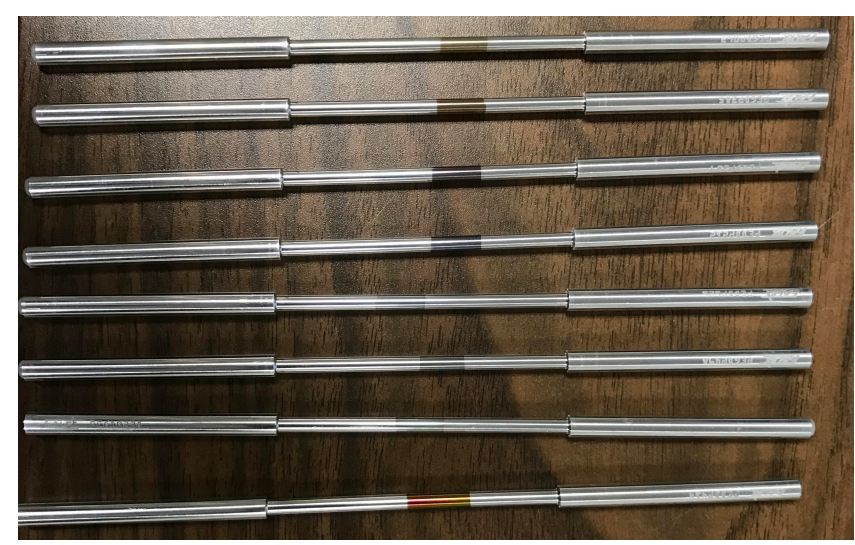

Figure 8: Reference tubes with theoretically known deposit thicknesses in order of increasing thickness from top to bottom (in order from top to bottom: tube ID 62, 385, 389, 212, 626, 498,228 , and 414)

\section{RESULTS AND DISCUSSION}

Figure 9 shows the qualitative thickness profile of a representative tube along with a picture of that same tube to show a typical result from this analysis, and additionally how the thickness profile and discoloration on the surface correlate. The intent of this figure is not to show quantitative data, but rather to show the relationship between the example tube and the thickness profile. The darker section of the deposit on the right side of the tube corresponds to the thicker portion of the deposit. Just to the left of the halfway point the deposit is no longer visible; however, a thin layer is still present as can be seen in the thickness profile. This highlights a benefit of the ellipsometric method as opposed to the color standard. Aspects of the film that are not visible to the eye can be analyzed using ellipsometry while the color standard method relies only on the capabilities of the human eye. 


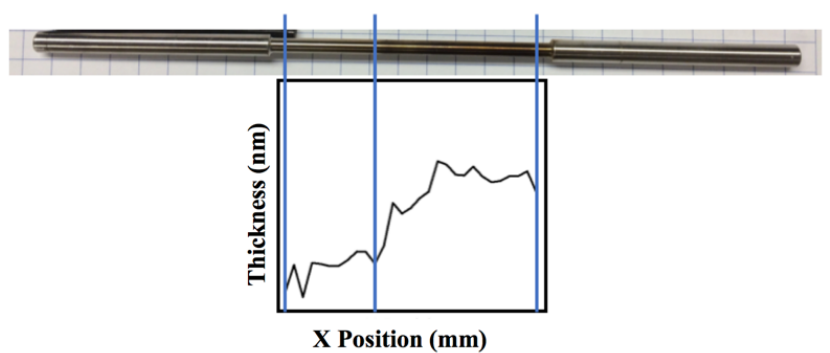

Figure 9: Tube discoloration and thickness profile. The darker parts of the deposit correspond to the thicker section (however there is deposit present on the section that is not discolored).

The uncertainty associated with the ellipsometric measurement of deposit thickness is difficult to quantify due to the fact that it is measured indirectly through optical modeling. Horiba Jobin Yvonne, the manufacturer of the ellipsometer used in this study, states in their user manual that the sensitivity of the instrument would be less than $\pm 0.5 \mathrm{~nm}$, and this is more directly related to the accuracy of the samples used to calibrate the instrument than the instrument itself. The uncertainty associated with the ellipsometer would be much smaller, however, the larger $\pm 0.5 \mathrm{~nm}$ is reported here.

The ellipsometric technique was applied to aluminum tubes exposed to Gevo jet fuel and JP-8 at temperatures ranging from 270 to $380{ }^{\circ} \mathrm{C}$. First, the effect of increasing temperature on pure Gevo was examined, and the results of these tests are summarized in Figure 10. In this figure, the thickness ( $t$ ) of the deposit is measured, and the estimated uncertainty is $\pm 0.5 \mathrm{~nm}$. Data sets for two circumferential locations are shown here and defined as follows: Position 1 is located in line with the serial number on the tube, and Position 3 is located $180^{\circ}$ away, on the opposite side of the tube. While there are minimal differences between the two positions, the same trends exist for both.

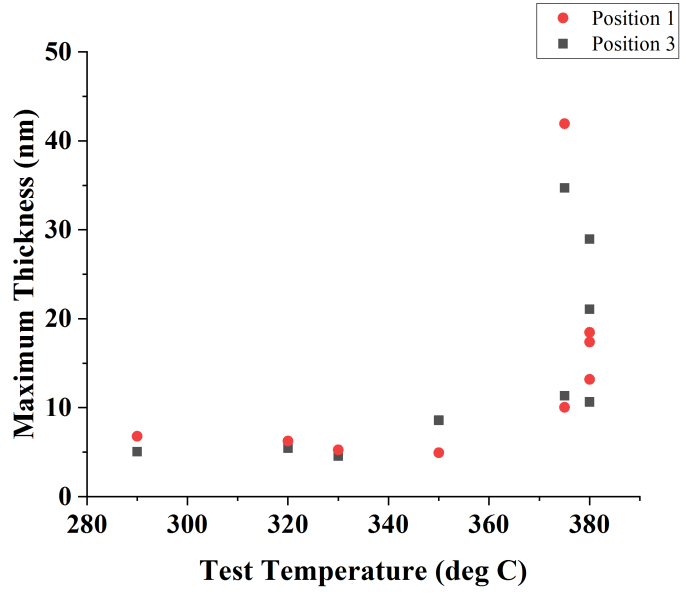

Figure 10: Maximum deposit thickness versus test temperature for pure Gevo fuel
The maximum deposit height is relatively constant until the temperature reaches approximately $375{ }^{\circ} \mathrm{C}$, at which point it increases rapidly. Additionally, the scatter in the data increases at higher temperatures. It should be noted that none of these tubes has a maximum deposit thickness of more than $85 \mathrm{~nm}$, so the thermal breakpoint temperature has not yet been reached. By extrapolating from this data, it can be assumed that the breakpoint would be reached quickly, given the drastic increase in deposit height measured at the higher temperatures.

For comparison, a similar analysis was performed on pure JP-8 fuel. JP-8 is a traditional kerosene based fuel commonly used by the United States military. The results are shown in Figure 11 and exhibit similar trends to the Gevo fuel. As in the previous discussion, in this figure, the thickness ( $t$ ) of the deposit is measured, and the estimated uncertainty is $\pm 0.5 \mathrm{~nm}$. In this case, the deposit thickness begins increasing at approximately $300{ }^{\circ} \mathrm{C}$, which is lower than that of the Gevo, and this set reaches a higher level of deposition more quickly. This fuel has also not yet reached its thermal breakpoint temperature because none of the samples show maximum deposit thicknesses greater than or equal to $85 \mathrm{~nm}$, but it can also be assumed that the thermal breakpoint would be shortly reached as in the previous case. These results indicate that the JP-8 is less thermally stable than the Gevo because its deposit thickness begins to increase rapidly at a lower temperature. This is as would be expected because the Gevo fuel contains lower levels of aromatics, which are known to negatively impact thermal stability.

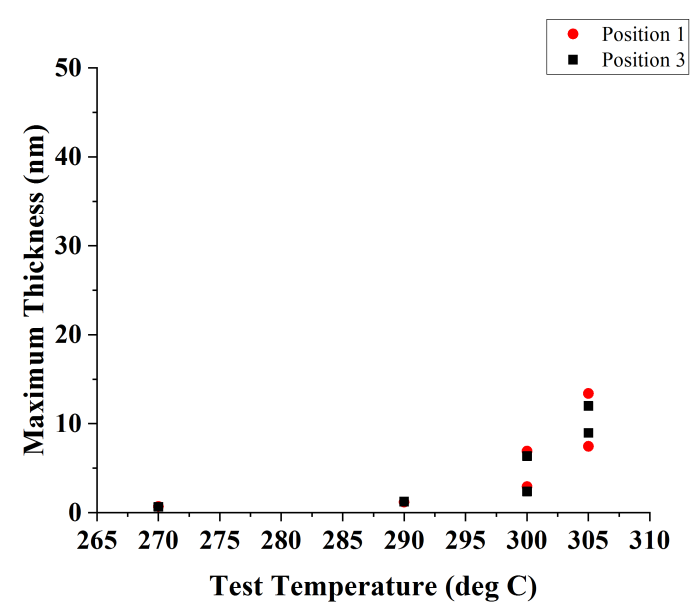

Figure 11: Maximum deposit thickness versus test temperature for JP-8.

The effect of increasing temperature on a blend of 85 percent Gevo with 15 percent JP-8 was also investigated. This investigation was carried out because alternative fuels are often blended with traditional fuels to normalize their properties and allow them to be used in conventional engines. The maximum deposit thickness is relatively constant with increasing temperature, as shown by Figure 12 . The 
uncertainty and measured variable are the same here as in the previous data sets. All three data sets have been graphed on the same vertical axis for ease of comparison.

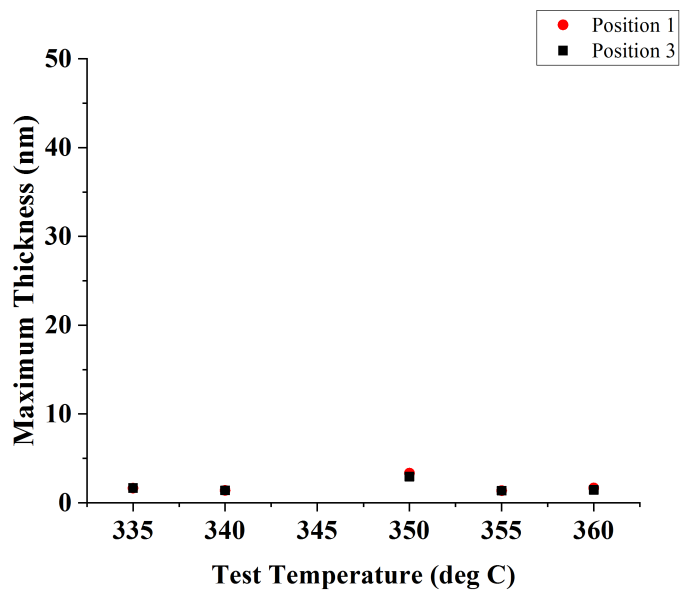

Figure 12: Deposit thickness versus test temperature for 85-15 blend of Gevo and JP-8

The thermal breakpoint is not reached by any of these samples either. The region shown here is probably still in the constant deposit region described for the two fuels shown above. If this is true, the blend of Gevo and JP- 8 would be more thermally stable than the JP-8, which makes sense given that the pure Gevo fuel was more thermally stable. The level of deposition in this blend is lower than for the pure Gevo fuel, but is roughly consistent with the level of the pure JP-8 prior to the $300{ }^{\circ} \mathrm{C}$.
Table 3: Gevo Color Rating Comparisons

\begin{tabular}{|c|c|c|c|c|}
\hline $\begin{array}{l}\text { Tube } \\
\text { ID }\end{array}$ & Fuel & $\begin{array}{l}\text { Color } \\
\text { Rating }\end{array}$ & $\begin{array}{l}\text { Max Thick } \\
(\mathrm{nm})( \pm 0.5 \\
\mathrm{nm})\end{array}$ & $\begin{array}{l}\text { Fuel } \\
\text { Temperature } \\
\left({ }^{\circ} \mathrm{C}\right)\end{array}$ \\
\hline 1229 & $\begin{array}{l}\text { N81 } \\
\text { GEVO }\end{array}$ & 2 (pass) & 5.0 (pass) & 290 \\
\hline 1230 & $\begin{array}{l}\text { N81 } \\
\text { GEVO }\end{array}$ & 2 (pass) & 5.5 (pass) & 320 \\
\hline 1231 & $\begin{array}{l}\text { N81 } \\
\text { GEVO }\end{array}$ & 1 (pass) & 4.6 (pass) & 330 \\
\hline 1234 & $\begin{array}{l}\text { N81 } \\
\text { GEVO }\end{array}$ & 1 (pass) & 8.6 (pass) & 350 \\
\hline 1235 & $\begin{array}{l}\text { N81 } \\
\text { GEVO }\end{array}$ & $\begin{array}{l}<2 \\
\text { (pass) }\end{array}$ & 34.7 (pass) & 375 \\
\hline 1238 & $\begin{array}{l}\text { N81 } \\
\text { GEVO }\end{array}$ & $\begin{array}{l}<2 \\
\text { (pass) }\end{array}$ & 29.0 (pass) & 380 \\
\hline 1257 & $\begin{array}{l}\text { N81 } \\
\text { GEVO }\end{array}$ & $\begin{array}{l}<2 \\
\text { (pass) }\end{array}$ & 21.1 (pass) & 380 \\
\hline 1260 & $\begin{array}{l}\text { N81 } \\
\text { GEVO }\end{array}$ & 2 (pass) & 11.4 (pass) & 375 \\
\hline 1262 & $\begin{array}{l}\text { N81 } \\
\text { GEVO }\end{array}$ & 1 (pass) & 10.7 (pass) & 380 \\
\hline 1232 & $\begin{array}{l}\text { N84 } \\
\text { JP-8 }\end{array}$ & 0 (pass) & 6.9 (pass) & 270 \\
\hline 1233 & $\begin{array}{l}\text { N84 } \\
\text { JP-8 }\end{array}$ & 1 (pass) & 11.9 (pass) & 290 \\
\hline 1241 & $\begin{array}{l}\text { N84 } \\
\text { JP-8 }\end{array}$ & 2 (pass) & 29.3 (pass) & 300 \\
\hline 1254 & $\begin{array}{l}\text { N84 } \\
\text { JP-8 }\end{array}$ & $\begin{array}{l}<3 \\
\text { (pass) }\end{array}$ & 69.2 (pass) & 300 \\
\hline 1243 & $\begin{array}{l}\text { N84 } \\
\text { JP-8 }\end{array}$ & $<4$ (fail) & 74.6 (pass) & 305 \\
\hline 1256 & $\begin{array}{l}\text { N84 } \\
\text { JP-8 }\end{array}$ & $<4$ (fail) & 134.0 (fail) & 305 \\
\hline 1271 & $\begin{array}{l}\text { N98 } \\
\text { GEVO- } \\
\text { JP-8 }\end{array}$ & $<3$ (pass) & 58.0 (pass) & 330 \\
\hline 1272 & $\begin{array}{l}\text { N98 } \\
\text { GEVO- } \\
\text { JP-8 }\end{array}$ & $<4$ (fail) & 50.4 (pass) & 335 \\
\hline 1275 & $\begin{array}{l}\text { N99 } \\
\text { GEVO- } \\
\text { JP-8 }\end{array}$ & $<4$ (fail) & 13.1 (pass) & 340 \\
\hline 1274 & $\begin{array}{l}\text { N99 } \\
\text { GEVO- } \\
\text { JP-8 }\end{array}$ & $<4$ (fail) & 15.7 (pass) & 345 \\
\hline
\end{tabular}

The Gevo and JP-8 samples provide an interesting opportunity to examine the color standard rating system. A summary of the color rating and maximum deposit thickness measured for each tube is given in Table 3. Generally, the maximum thickness increases with increasing color rating, and the color rating increases with increasing test temperature. This indicates that thicker deposits are generally darker in color than thinner ones. However, there are instances where the two 
rating systems disagree. Tube 1243 for instance, fails the color standard test with a rating of $<4$, but passes the ellipsometric test with a maximum thickness of 74.62. Tubes 1274 and 1275 also fall into this category of failing the color test but passing the ellipsometric test. These two tubes in fact have quite low maximum deposit thicknesses, highlighting how the color test can be misleading and inaccurate. It is likely that the Gevo deposits do not follow the same color trends as traditional fuels, making the color standard incapable of rating them accurately. The tubes receiving $<4$ ratings span a deposit thickness range of 13.059 to $134.034 \mathrm{~nm}$, demonstrating how the color standard groups tubes together that are much more different than they are alike. This emphasizes the need for a more detailed test, such as ellipsometry.

\section{CONCLUSIONS}

It was demonstrated using ellipsometry that deposit thickness increases with increasing test temperature for Gevo and JP-8 jet fuels on aluminum tubes. The deposit levels were constant up to a particular temperature (fuel dependent) and then increase exponentially. This temperature was approximately $375{ }^{\circ} \mathrm{C}$ and $300{ }^{\circ} \mathrm{C}$ for pure Gevo and JP-8 fuels, respectively. The results of the color standard test were compared to the ellipsometric thickness measurements, and several cases where the two disagree were highlighted. The Tauc-Lorentz dispersion optical model used to make these measurements was validated using reference tubes with known deposit thicknesses.

Effort is currently being undertaken to characterize the thermal stability of various alternative jet fuels and additives using ellipsometry. Future work in this area will focus on further refinement to the optical models used and extending the technique to other fuels and substrates.

\section{ACKNOWLEDGMENTS}

This material is based upon work supported by the National Aeronautics and Space Administration under Grant Number NNX15AU28H issued through the NASA Education Minority University Research Education Project (MUREP) through the NASA Harriett G. Jenkins Graduate Fellowship activity. The authors thank Michelle Sestak and Celine Eypert of Horiba Scientific, and Tim Edwards, Zachary West, and Linda Shafer from Wright Patterson Air Force Base for their assistance.

\section{REFERENCES}

[1] Colket, M. B., Heyne, J., Rumizen, M., Edwards, J. T., Gupta, M., Roquemore, W. M., Moder, J. P., Tishkoff, J. M., and Li, C., "An overview of the national jet fuels combustion program," Proc. 54th AIAA Aerospace Sciences Meeting, p. 0177 .
[2] ASTM Standard D3241, 2015, "Standard Test Method for Thermal Oxidation Stability of Aviation Turbine Fuels (JFTOT Procedure)," ASTM International, West Conshohocken, PA, 2003, DOI:10.1520/D3241-08, www.astm.org.

[3] Baker, C., David, P., Taylor, S., and Woodward, A., "Thickness measurement of JFTOT tube deposits by ellipsometry," Proc. Proceedings of the 5th International Conference on Stability and handling of liquid fuels, Department of Energy Washington, DC, pp. 433-447.

[4] Nash, L., Klettlinger, J., and Vasu, S., 2017, "Ellipsometric Measurements of the Thermal Stability of Alternative Fuels," Journal of Energy Resources Technology, 139(6), pp. 062207062207-062208.

[5] Nash, L., and Vasu, S., 2017, "Thermal Stability Measurement of Alternative Jet Fuels Using Ellipsometry," (50831), p. V003T003A003.

[6] Browne, S. T., Wong, H., Hinderer, C. B., and Klettlinger, J., 2012, "Enhancement of Aviation Fuel Thermal Stability Characterization Through Application of Ellipsometry."

[7] "Tauc-Lorentz Dispersion Formula," TN 11, Horiba, Nov. 2006. 